\title{
Hama pada Cabai Merah
}

\author{
Didi Budi Cahyono선 Hasna Ahmad² dan A. R Tolangara ${ }^{3}$ \\ 1SMA Muhammadiyah Subaim \\ 2,3 Program Studi Pendidikan Biologi Universitas Khairun \\ *Corresponding authors: arbatata@yahoo.co.id \\ Manuscript received: 15-07-2017 Revision accepted: 24-08-2017
}

\begin{abstract}
Abstrak
Hama merupakan hewan yang merusak tanaman dan umumnya merugikan para petani dari segi ekonomi, maka manusia selalu akan memperhatikannya, guna meningkatkan hasil pertanian, jika tidak hasil panennya akan menurun. Adapun tujuan penelitian inim untuk mengetahui keanekaragaman jenis hama yang menyerang tanaman cabai merah. Metode penelitian ini bersifat deskriptif kualitatif, dengan menggunakan perhitungan indeks keanekaragaman jenis. Hasil penelitian menunjukkan bahwa Jenis hama yang ditemukan pada tanaman cabe merah terdiri dari jenis Locusta migratoria manilensis, Gryllus mitratus, Grylloptalpa africana, Lycosa sp, Spodoptera litura L., Mycus percicae, Planococus citri, Aulocophora $\mathrm{sp}$, Epilachna argus. Populasi hama tertinggi adalah ulat grayak (Spodoptera litura L.) dan jenis yang memiliki populasi terendah yaitu orong-orong (Grylloptalpa africana). Keankaregaman jenis hama pada tanaman cabe merah memiliki nilai keragaman sebesar $\mathrm{H}^{\prime}=1,825$, maka dikategorikan keanekaragaman jenis sedang.
\end{abstract}

Kata kunci: Jenis hama, Tanaman Cabe, Keanekaragaman jenis

\begin{abstract}
Pest is a destructive animal for plants and is generally harming the farmers in terms of economic aspect. Thus, people always put their attention to it in order to increase the produce otherwise the harvest will be decreased. The research aimed to find out the diversity of pest type attacking chili pepper crop. The research method was qualitative descriptive using the calculation of diversity index. The research result indicates that the types of pest found in chili pepper crop were: Locusta migratoria manilensis, Gryllus mitratus, Grylloptalpa africana, Lycosa sp, Spodoptera litura L., Mycus percicae, Planococus citri, Aulocophora sp, and Epilachna argus. The highest population was taro caterpillar (Spodoptera litura L.) and the lowest was mole cricket (Grylloptalpa Africana). The diversity of pest in chili pepper has diversity value of $\mathrm{H}^{\prime}=1.825$ and it categorized as medium diversity.
\end{abstract}

Keywords: Type of pest, Chili pepper, Type diversity 


\section{PENDAHULUAN}

Hama merupakan hewan yang merusak tanaman dan umumnya merugikan para petani dari segi ekonomi, maka manusia selalu akan memperhatikanya, guna meningkatkan hasil pertanian, jika tidak maka hasil panennya akan menurun. Beberapa contoh akibat serangan hama pada tanaman cabai misalnya: serangan hama pada bagian akar tanaman cabai menyebabkan proses penyerapan unsure hara, air dan lain-lain terganggu, serangan hama pada bagian batang tanaman cabai menyebabkan transportasi zat makanan terganggu atau berhenti sama sekali sehingga tanaman menjadi layu dan mati, serangan hama pada bagian daun tanaman cabai dapat menyebabkan terganggunya proses fotosintesis dan serangan hama pada buah cabai dapat menyebabkan buah rusak atau gugur, semuanya akan mempengeruhi menurunnya nilai ekonomi.

Besar kerugian yang dialami petani cabai dipengaruhi oleh jenis hamanya, jenis yang dimaksud adalah hama tersebut termasuk hama utama, hama sementara, atau hama pindahan (Anonim, 1992 ). Hama utama adalah hewan yang memakan tanaman. Hama sementara sebenarnya keberadaanya telah lama, tetapi karena populasinya yang sedikit menyebabkan kerugian yang ditimbulkan tidak berarti. Namun, karena ada gangguan seperti perubahan musim, iklim, kegiatan manusia yang salah, atau pengendalian hama yang keliru. Populasi hama ini dapat meningkat, maka kerugian yang ditimbulkan juga meningkat. Hama pindahan merupakan hama yang suka berpindah seperti ulat grayak, belalang dan burung. Karena sifat yang suka berpindah tempat ini, maka serangannya tidak dapat diduga.

Cabai merah merupakan salah satu jenis sayuran yang dibudidayakan secara komersial di daerah tropis. Kegunaannya sebagian besar untuk konsumsi rumah tangga dan sabagian lagi di ekspor ke negara-negara beriklim dingin dalam bentuk kering. Cabai merah keriting tersebut digunakan untuk bumbu penyedap saus dan produk-produk makanan kaleng (Santika, 2002). Cabai menduduki areal paling luas di antara sayuran yang di budidayakan di Indonesia. Menurut Pickersgill (2002) terdapat 5 spesies cabai yang didomestikasi, yaitu Capsicum Annum, Capsicum Frutescens, Capsicum Chinense, Capsicum Bacetum, dan Capsicum Pubescens. Diantara kel;ima spesies tersebut yang memiliki potensi ekonomis adalah Capsicum Annum dan Capsicum Frutescens. Kedua spesies ini dibudidayakan secara luas di seluruh dunia. Spesies yang lain Capsicum Chinense dan Capsicum Bacetum terbatas di amerika selatan saja. Adapun tujuan dari penelitian adalah ini untuk mengetahui keanekaragaman jenis hama yang menyerang tanaman cabai merah.

\section{METODE PENELITIAN}

Adapun cara pengamatan haha pada tanaman cabai adalah hama pada daun, batang dan buah. Hama yang terdapat pada daun, batang dan buah diambil menggunakan pinset, jenis hama yang ditemukan dimasukkan ke dalam botol ampul yang telah berisi kapas dan dibasahi alkohol 70\%, kemudian hama tersebut diidentikasi dengan mengavu pada buku kunci identifikasi serangga Karangan boror (1992). Hama yang aktif di udara di tangkap dengan menggunakan jaring serangga (trap insect), kemudian dimasukkan ke dalam botol ampul yang telah berisi kapas dan dibasahi alkohol 70\%, kemudian hama tersebut diidentikasi, sedangkan hama yang terdapat di dalam tanah ditangkap dengan alat jebakan atau pitfall trap, dengan menggunakan gelas plastik, kemudian gelas tersebut diisi dengan alkohol 70\% sebanyak $100 \mathrm{ml}$, setelah itu di tanam dalam bedengan, permukaan gelas di tanam rata dengan permukaan tanah. Setiap bedengan dipasang 2 alat jebakan hama (pittfall trap), hama yang terjebak diambil dan dimasukkan ke dalam botol ampul yang berisi kapas dan dibasahi alkohol 70\%, kemudian diidentifikasi lebih lanjut. Setelah data pengamatan diperoleh, 
kemudian dianalisis menggunakan rumus indeks keragaman $\left(\mathrm{H}^{\prime}\right)$ menurut Shanon-Wienner dalam Odum (1993).

$$
H^{\prime}=-\sum\left\{\left(\frac{n i}{N}\right) \operatorname{In}\left(\frac{n i}{N}\right)\right\}
$$

Dimana :

$$
\begin{array}{ll} 
& \mathrm{H}^{\prime}=\text { Indeks keragaman } \\
\text { ni=Jumlah total individu dari suatu spesies } \\
\text { Jika } \quad
\end{array} \begin{aligned}
& \mathrm{N}=\text { Jumlah total individu dari seluruh spesies } \\
& \mathrm{H}^{\prime}<1 \quad: \text { Keragaman rendah } \\
& \\
& \mathrm{H}^{\prime}=1-3 \quad \text { : Keragaman sedang } \\
& \mathrm{H}^{\prime}>3: \text { Keragaman tinggi }
\end{aligned}
$$

\section{HASIL DAN PEMBAHASAN}

Jenis hama yang menyerang tanaman cabai merah (Capsicum annum L.) ditemukan sebanyak 9 (sembilan) jenis yang tergabung dalam 9 famili. Jenis hama serta jumlah individunya dapat dilihat pada Tabel 1 berikut:

Tabel 1. Jenis hama yang menyerang tanaman cabai merah

\begin{tabular}{clllc}
\hline No & Nama Indonesia & Nama Latin & Tempat Ditemukan & Jumlah \\
\hline 1 & Belalang & Locusta migratoria manilensis & Daun muda & 75 \\
2 & Jangkrik & Gryllus mitratus & Tanah & 28 \\
3 & Orong-orong & Grylloptalpa africana & Tanah & 4 \\
4 & Laba-laba & Lycosa sp & Batang dan daun & 27 \\
5 & Ulat grayak & Spodoptera litura L. & Daun & 100 \\
6 & Kutu daun & Mycus percicae & Daun & 24 \\
7 & Kutu putih & Planococus citri & Daun & 8 \\
8 & Kumbang koksi & Aulocophora sp. & Daun & 12 \\
9 & Kumbang oteng & Epilachna argus & Daun & 31 \\
\hline
\end{tabular}

Hama pada tanaman cabai yang memiliki populasi tertinggi adalah ulat grayak (Spodoptera litura L.) dan jenis yang memiliki populasi terendah yaitu jenis orong-orong (Grylloptalpa africana), perbedaan jumlah ini menunjukkan bahwa jenis-jenis tertentu populasinya meningkat karena adanya sumber makanan yang cocok untuk memacu pertambahan populasinya, dalam hal ini jumlah individu tiap jenis akan bertambah sesuai dengan ketersediaan sumberdaya dari lingkungan, dengan sumberdaya tersebut akan meningkatkan populasinya.

Setiap hama mempunyai kebutuhan yang sama dalam memperoleh makanan, sehingga populsi meningkat sedangkan ruang hidup menjadi sempit karena. Hal ini sejalan dengan pendapat Rukmana (1997), bahwa tanaman akan menjadi sumber makanan dan tempat tinggal organisme-organisme hidup, bila tanaman dalam suatu areal jumlahnya banyak maka populasi hama meningkat, begitu pula sebaliknya. Uraian tentang jenis-jenis hama yang ditemukan pada tanaman cabai merah beserta gambar dan klasifikasinya adalah sebagai berikut. 


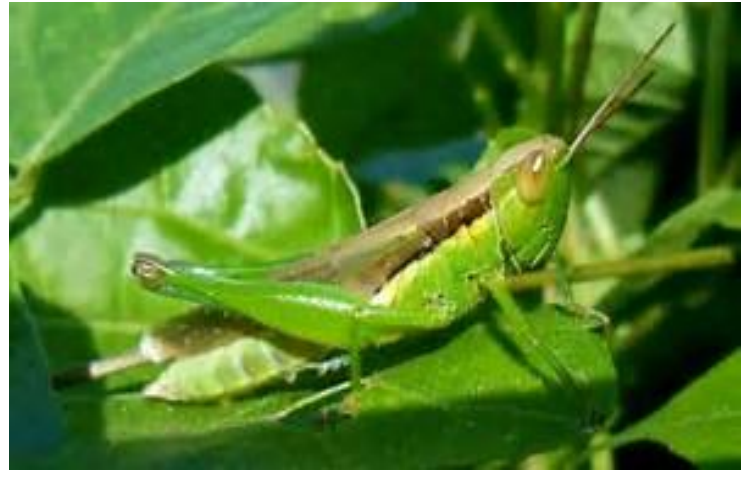

Gambar 1. Locusta magratoria manilensis

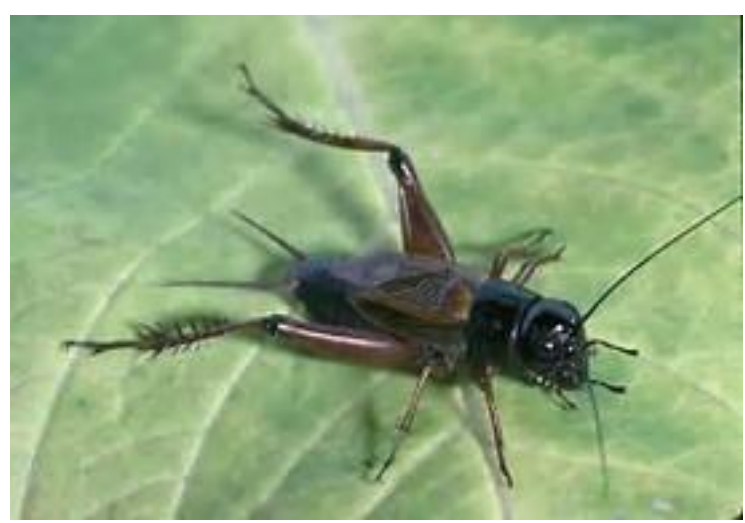

Gambar 2. Gryllusmitratus

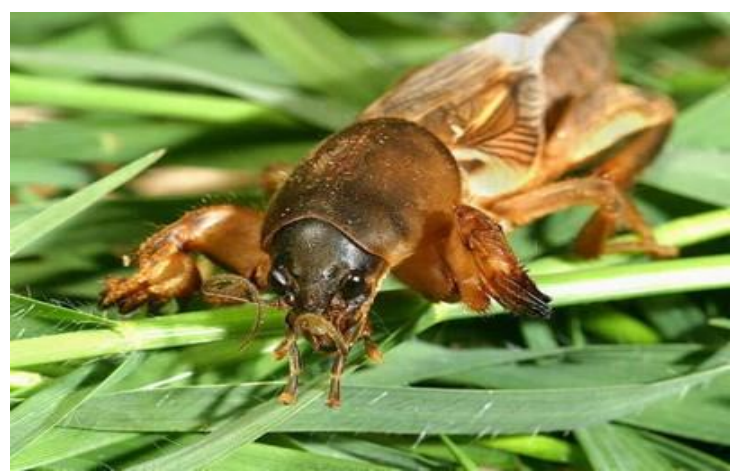

Gambar 3. Gryllotalpa africana.

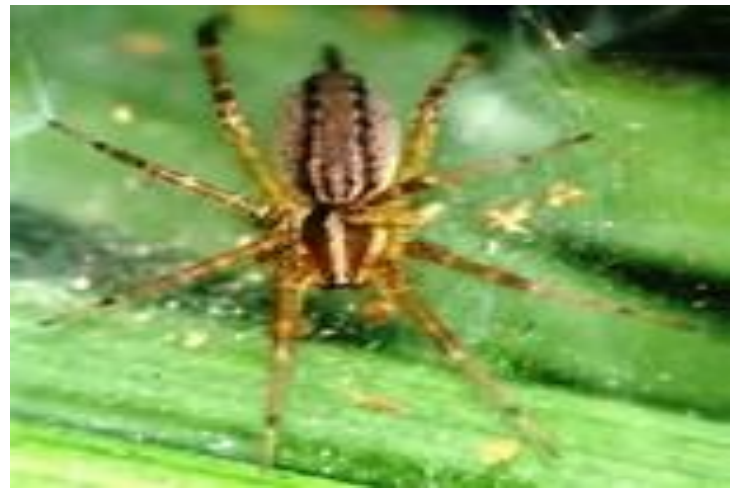

Gambar 4. Lycosa sp.
Klasifikasi

Kingdom : Animalia

Filum : Arthropoda

Klass : Insekta

Ordo : : Orthopera

Famili : Acrididae

Genus : Locusta

Spesies : Locustamagratoria manilensis
Klasifikasi

Kingdom : Animalia

Filum : Arthropoda

Klas : Insekta

Ordo : Orthopera

Famili : Gryllidae

Genus : : Gryllus

Spesies : Gryllusmitratus
Klasifikasi

Kingdom : Animalia

Filum : Arthropoda

Klas : Insekta

Ordo : Orthoptera

Famili : Grillotalpidae

Genus : Gryllotalpa

Spesies : Gryllotalpa africana

$\begin{array}{ll}\text { Klasifikasi } & \\ \text { Kingdom } & \text { : Animalia } \\ \text { Filum } & \text { : Arthropoda } \\ \text { Klas } & \text { : Insekta } \\ \text { Ordo } & \text { : araneae } \\ \text { Famili } & \text { : Lycosidae } \\ \text { Genus } & \text { : Lycosa } \\ \text { Spesies } & \text { : Lycosa } \mathrm{sp}\end{array}$




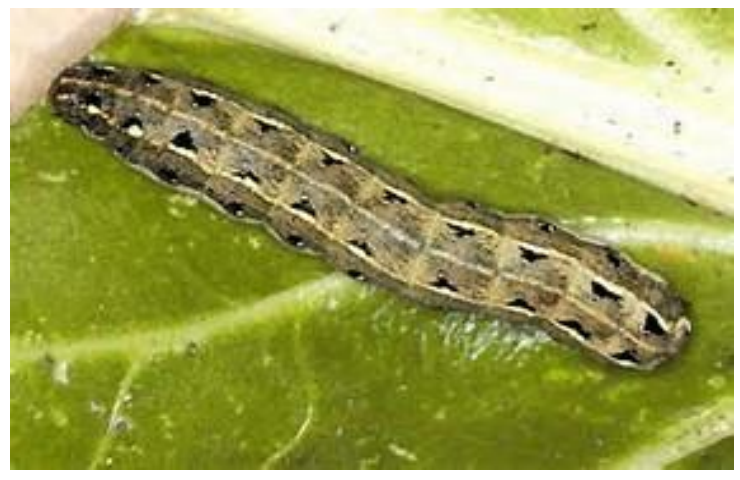

Gambar 5. Spodoptera litura L.

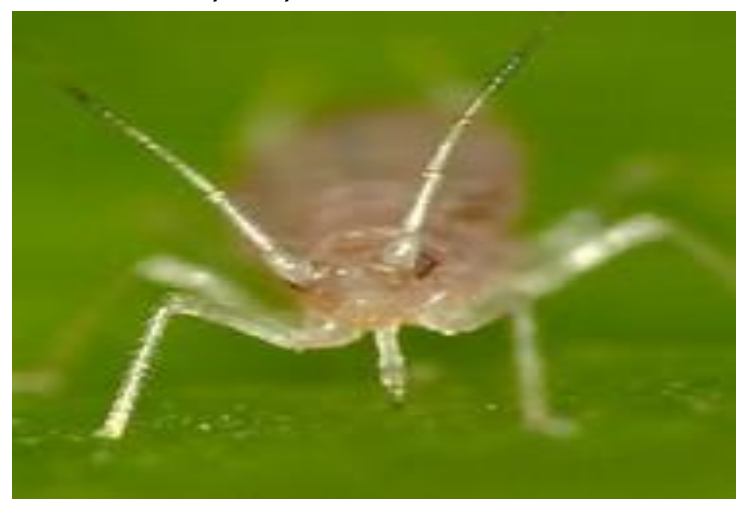

Gambar 6. Myzus percicae

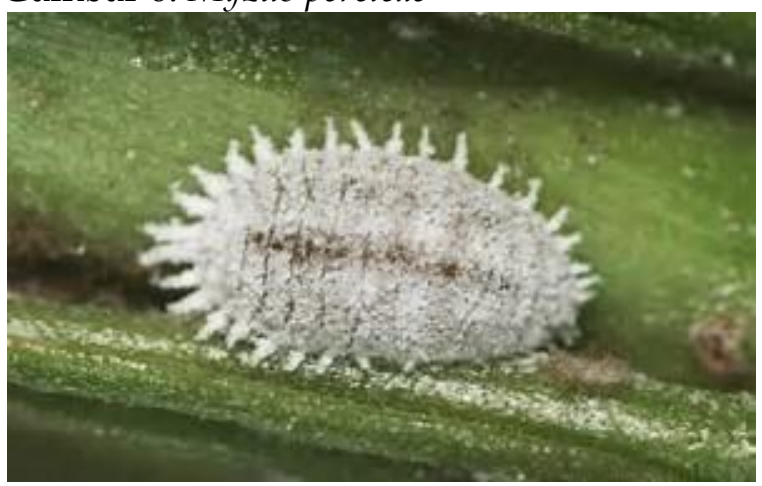

Gambar 7. Planococcus citri

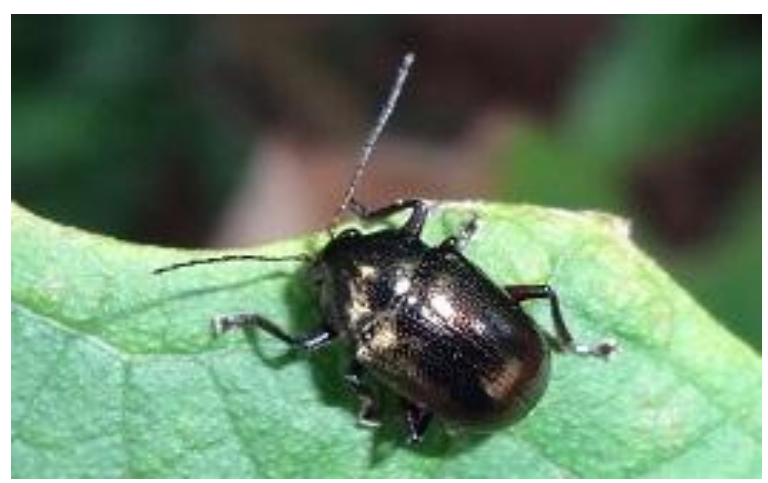

Gambar 8 Aulacophora sp

$\begin{array}{ll}\text { Klasifikasi } & \\ \text { Kingdom } & \text { : Animalia } \\ \text { Filum } & \text { : Arthropoda } \\ \text { Klas } & \text { : Insekta } \\ \text { Ordo } & \text { : Coleoptera } \\ \text { Famili } & \text { : Noetoidae } \\ \text { Genus } & \text { : Spodoptera } \\ \text { Spesies: } & \text { Spodoptera litura L. }\end{array}$

Klasifikasi

Kingdom : Animalia

Filum : Arthropoda

Klas : Insekta

Ordo : : Homoptera

Famili : Carcopidae

Genus : : Myzus

Spesies : Myzus percicae

Klasifikasi

Kingdom : Animalia

Filum : Arthropoda

Klas : Insekta

Ordo : Homoptera

Famili : Pseudococcidae

Genus : Pseudococcus

Spesies : Planococcus citri

Klasifikasi

Kingdom : Animalia

Filum : Arthropoda

Klas : Insekta

Ordo : Coleoptera

Famili : Chrysomelidae

Genus : Aulacophora

Spesies : Aulacophora sp 


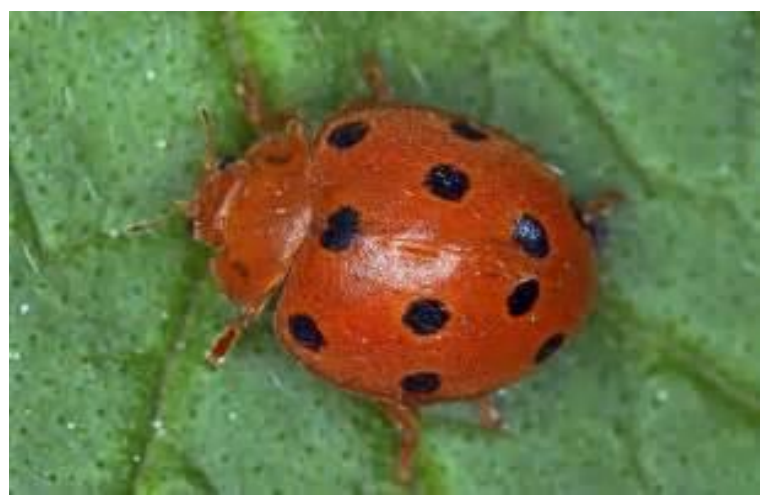

$\begin{array}{ll}\text { Klasifikasi } & \\ \text { Kingdom } & \text { : Animalia } \\ \text { Filum } & \text { : Arthropoda } \\ \text { Klas } & \text { : Insekta } \\ \text { Ordo } & \text { : Coleoptera } \\ \text { Famili } & \text { : Coccinellidae } \\ \text { Genus } & \text { : Epilachna } \\ \text { Spesies: } & \text { : Epilachna argus }\end{array}$

Gambar 9. Epilachna argus

Berdasarkan hasil pengamatan yang tertera pada Tabel 1, kemudian data tersebut dianalisis untuk mengetahui nilai keanekaragaman tiap jenis dan hasilnya disajikan Tabel 2.

Tabel 2. Nilai keanekaragaman jenis hama pada tanaman cabai merah.

\begin{tabular}{|c|c|c|c|c|c|c|c|c|c|c|c|c|c|}
\hline No & Nama Jenis & Jun & lah & nd & idu & tia & jen & $\mathrm{H}$ & & & & Jlh & $\mathrm{H}^{1}$ \\
\hline 1 & $\begin{array}{l}\text { Locusta migratoria } \\
\text { manilensis }\end{array}$ & 10 & 9 & 6 & $\begin{array}{l}1 \\
2\end{array}$ & 5 & 6 & 8 & 4 & 6 & 9 & 75 & 0,342 \\
\hline 2 & Gryllus mitratus & 4 & 2 & 2 & 2 & 2 & 3 & 2 & 3 & 5 & 3 & 28 & 0,216 \\
\hline 3 & Grylloptalpa africana & - & - & - & - & 1 & - & 2 & - & 1 & - & 4 & 0,02 \\
\hline 4 & Lycosa sp & 4 & 2 & 3 & 1 & 4 & - & 4 & 2 & 3 & 4 & 27 & 0,212 \\
\hline 5 & Spodoptera litura L. & 13 & 9 & 8 & $\begin{array}{l}1 \\
3\end{array}$ & 6 & $\begin{array}{l}1 \\
4\end{array}$ & 8 & $\begin{array}{l}1 \\
0\end{array}$ & $\begin{array}{l}1 \\
1\end{array}$ & 8 & 100 & 0,364 \\
\hline 6 & Mycus percicae & 4 & 4 & - & 2 & 4 & - & 7 & 3 & - & - & 24 & 0,196 \\
\hline 7 & Planococus citri & - & 1 & 1 & 1 & - & - & 4 & - & - & 1 & 8 & 0,091 \\
\hline 8 & Aulocophora sp & 2 & - & 2 & 1 & - & 3 & 3 & - & 1 & - & 12 & 0,123 \\
\hline \multicolumn{12}{|c|}{ Jumlah } & $\begin{array}{l}31 \\
309\end{array}$ & $\begin{array}{l}0,229 \\
1,825\end{array}$ \\
\hline
\end{tabular}

Berdasarkan hasil analisis tentang keanekaragaman jenis hama pada tanaman cabai merah, secara keseluruhan menunjukkan bahwa nilai keanekaragaman jenis hama sebesar 1,825 maka dikategorikan keanekaragaman jenis sedang, hal ini sejalan dengan pendapat ShanonWienner dalam odum (1993) yang menyatakan bahwa suatu komunitas memiliki tingkat keanekaragaman jenis yang tinggi bila $\mathrm{H}^{\prime}$ mencapai $>3,0$. Sedangkan hasil penelitian menunjukkan keanekaragaman jenis hama pada tanaman cabai merah, hal ini disebabkan karena terjadinya kompetisi intraspesis dan kompetisi interspesis, dalam kompetisi terdapat proses makan dan dimakan dalam suatu komunitas. Pada tanaman cabai hama-hama yang ada biasanya dimangsa oleh jenis burung tertentu, sehingga menyebabkan keanekaragaman jenis hama di lokasi penelitian makin berkurang, berkuranganya jumlah individu maupun spesies ini maka akan bedampak keanekaragaman jenis yang tergolong sedang.

Keanekaragaman jenis memberi gambaran tentang perubahan-perubahan dalam komunitas pada tiap jenis, perubahan tersebut terjadi dalam suatu komunitas akibat persaingan dalam memperoleh makanan (sumberdaya), maupun ruang serta menggambarkan pola penyebaran dari individu-individu pada suatu jenis (Krebs,1989). Keanekragaman jenis sedang pada hama yang menyerang tanaman juga dapat terjadi karena tidak adanya pemerataan jumlah individu dalam suatu komunitas. Hal ini sejalan dengan pendapat Joesi (2002) bahwa keragaman jenis pada kelompok hama dapat terjadi karena penyebaran invidu yang tidak merata dalam suatu 
komuitas, penyebaran yang tidak merata ini dapat terjadi mudah untuk dipahami, karena peneyebaran invidu tiap jenis cenderung terpisah dari kelompoknya untuk mencari makan secra individu, dan bukan secara berkelompok.

Berdasarkan uraian di atas maka jenis hama yang ditemukan pada tanaman cabai merah dilokasi penelitian dalam jumlah yang banyak adalah hama perusak akar, batang dan daun cabai dengan cara memakannya sehingga akan berpengaruh pada nilai ekonomi pada tanaman. Ini sejalan dengan pendapat Cahyono, (2003) bahwa kerugian akibat rusaknya tanaman cabai, sehingga akan menurunkan nilai ekonomi dari tanaman tersebut. Sehingga keragaman jenis hama akan mempengaruhi nilai ekonomi masyarakat petani.

\section{SIMPULAN}

Berdasarkan hasil penelitian dan pembahasan, maka dapat simpulkan sebagai berikut:

1. Jenis hama yang ditemukan pada tanaman cabe merah terdiri dari jenis Locusta migratoria manilensis, Gryllus mitratus, Grylloptalpa africana, Lycosa sp, Spodoptera litura L., Mycus percicae, Planococus citri, Aulocophora sp, Epilachna argus,

2. Populasi hama tertinggi adalah ulat grayak (Spodoptera litura L.) dan jenis yang memiliki populasi terendah yaitu orong-orong (Grylloptalpa africana),

3. Keankaregaman jenis hama pada tanaman cabe merah memiliki nilai keragaman sebesar $\mathrm{H}^{\prime}$ $=1,825$, maka dikategorikan keanekaragaman jenis sedang.

\section{DAFTAR PUSTAKA}

Anonim, 1992.Khsanah Pengetahuan Serangga. Tira Pustaka, Jakarta

Boror J.D, dkk, 1992. Pengenalan Pelajaran Serangga. Gajah Mada University Press, Yogyakarta.

Cahyono B, 2003. Teknik Budidaya dan Analisis Usaha Tani Cabai Rawit. Kanisus, Yogyakarta.

Endah H, Joesi, 2002. Mengendalikan Hama dan Penyakit Tanaman.Agromedia Pustaka, Jakarta.

Odum EP, 1993. Dasar-Dasar Ekologi. Gajah Mada University Press, Yogyakarta.

Prajnanta F, 2006. Mengatasi Permasalahan Bertanam Cabai. Penebar Swadaya, Jakarta

Rukmana R dan Sugandi U.S., 1997. Hama Tanaman Dan Teknik Pengendalianya, Kanisius, Yogyakarta.

Santika A., 1995. Agribisnis Cabai, Penebar Swadaya, Jakarta. 